Author Post-Print

\title{
Cross-Cultural Psychogerontology
}

Isabelle Albert ${ }^{1}$ and Clemens Tesch-Römer ${ }^{2}$

${ }^{1}$ University of Luxembourg, Esch-sur-Alzette, Luxembourg, Isabelle.Albert@uni.lu

${ }^{2}$ German Centre of Gerontology, Berlin, Germany, clemens.tesch-roemer@dza.de

Synonyms: Cross-Cultural Psychology of Aging; Cross-Cultural Geropsychology; Psychological Aging Across Cultures

\section{Definition}

Cross-Cultural Psychogerontology deals with universals and differences in psychological aspects of aging across cultures.

\section{Overview}

Population aging is a phenomenon that affects most parts of the world. According to recent data from the World Population Prospects (United Nations 2017), the number of older persons - those aged $60+$ - has reached 962 million worldwide and is expected to climb to 2.1 billion in 2050. In spite of these general world trends, life expectancies differ still largely and aging remains a highly diverse experience across the world. Whilst universal developmental tasks are markers for older 
age in all societies (e.g. becoming a grandparent), expectations with regard to typical life trajectories and the timing of transitions vary. This "social clock" (Neugarten et al. 1965) or “cultural chrononormativity of aging" (Brinkmann and Musaeus 2018) is also expressed in legal regulations and policies (e.g. availability and timing of retirement schemes). Normative and nonnormative life events and their interpretation as on-time or off-time might thus be defined very differently depending on the cultural (and historical) context (see also Baltes et al. 1980; Wrosch and Heckhausen 2005).

This leads to one of the central questions of cross-cultural aging research: Are aging processes universals across cultures and societies in the Western and Eastern, Northern and Southern parts of the world-or do aging processes differ between cultures and societies? If culture-specific differences are found, age seems to be at least partly a social construction and social age might hence be a more appropriate indicator than chronological age here. Given cultural and societal differences, an important task of cross-cultural psychogerontology is the identification of underlying cultural and societal factors (e.g. Bleidorn et al. 2016). The knowledge of these factors might give insight into age as social construction - and possibly also indications for potential societal interventions (Kemper et al. 2016).

Early life-course theories defined specific developmental tasks based on biological factors and social expectations (see Erikson 1968), and the consideration of historical and socio-cultural context is a principle of life-span psychology (Baltes et al. 1980). It is therefore astounding that only recent research has systematically addressed cross-cultural differences in aging, whereas most theories stem from a Western perspective.

Cross-cultural psychogerontology starts from the theoretical assumption that individual development over the life span takes place in social contexts that differ in their emphasis of 
individuals' embeddedness into social groups and societal context, often operationalized as collectivist vs. individualist cultures (Kanagawa et al. 2001; Mayer et al. 2012; Triandis 2001). In individualist, mostly Western cultures developmental pathways of independence are emphasized, stressing autonomy, personal choice and self-fulfillment, whereas in collectivist, mostly Eastern cultures, interdependence is emphasized, highlighting obligations towards others and social harmony (Greenfield et al. 2003; Rothbaum et al. 2000). Thus, culture assumes the role of a "canalizer" that provides constraints which guide human development in a certain direction, however without exactly determining development (Valsiner 1996). Hence, both universals and differences in psychological aspects of aging might be observed across cultures.

\section{Key Research Findings}

\section{Views on aging}

Views on aging have a double impact on individual development over the life span: they might bias behavior toward older people through stereotypes, prejudice or ageism (Chasteen et al. 2015), and they can influence older adults' self-concepts through internalization and self-stereotyping (Kornadt and Rothermund 2015). It has been argued that in traditional and Eastern societies more favorable views toward older adults and aging might be prevalent, for instance due to Confucian values of filial piety, a concept that refers to life-long mutual obligations and respect toward elder family members, typical for East Asian cultures such as China, Korea and Japan (Hwang, 1999). A meta-analysis by North and Fiske (2015) including 37 papers and 23 countries, however, challenges this assumption: contrary to expectations, participants in Northern American and anglophone countries were found to show generally less negative attitudes toward older adults, whereas most negative views were documented for East Asians. Europeans were most negative in the West and East Asians more negative than South-East Asians. The speed of population ageing 
was related with ageism on aggregate level. Nonetheless, it might be important to look at different areas of development here. For instance, Löckenhoff and colleagues (2009) found in their college student sample from 26 countries more negative ratings with regard to age-related changes in attractiveness, everyday tasks and new learning — all related to biologically based processes, whereas expectations of increases with age were found for general knowledge, wisdom, and respect-hence more culturally based aspects. Culture-level indicators and perceptions of aging were weakly linked in physical and cognitive areas, but more strongly related regarding socioemotional aspects and societal views.

\section{Cognitive processes}

It has been argued that - in line with the distinction between mechanics and pragmatics (Baltes 1993) of cognitive functioning, the lifelong accumulation of cultural knowledge would lead to larger cross-cultural differences in the pragmatics of cognition with age. Park et al. (1999) have developed a framework model suggesting that different age trajectories might also be task-specific. Whereas effortful and controlled tasks that are highly resource demanding would show smaller cultural differences in older age due to universal biologically based decline, older adults would profit from their lifelong cultural experiences in tasks that involve automatically activated processes which reduce the cognitive effort needed to carry out a specific task. Accordingly, older adults from Eastern vs. Western contexts differed more strongly compared to younger individuals with regard to recall of material that belongs to taxonomic categories (e.g. grouping animals with similar characteristics). The use of such categories is more common in Western compared to Eastern contexts and as categorical information can help to recall information, Westerners who employ this strategy automatically might need less cognitive resources compared to Easterners who are less experienced in the use of categorical information (see Fang et al. 2017). Culture- 
specifics of neurocognitive aging have also been demonstrated in cross-cultural neuroimaging studies where for instance East-West differences in older adults' activation of object processing areas were found (Park and Gutchess 2006).

\section{Social relations}

Socio-emotional selectivity theory (Carstensen et al. 2003) posits that the size of social networks diminishes with age, whereas existing relations with close social partners are strengthened - a pattern that has been typically found in Western contexts. In the collectivist context of China, these associations between number of network partners (peripheral and close) and age were only found for participants who were low in interdependence, whereas larger social networks were found for older participants with medium or high levels of interdependence (see also Ajrouch et al. [2018] for Japan, Lebanon, Mexico, US). Different meanings of social relations could be at the core of such differences: Westerhof et al. (2000) report that US older adults described social relations more in their function for emotional regulation, whereas for Congolese elders, the meaning of social relations was more instrumental. Social relations might thus serve diverse goals (e.g. emotional vs. old-age security value of children, Kağıtç̧başı 1982) and these could be satisfied by different strategies regarding social networks across age.

\section{Subjective well-being}

Regarding cross-cultural differences in subjective well-being, Karasawa et al. (2011) expected more positive age trajectories for Japanese compared to US elders in particular regarding eudaimonic aspects due to cultural values attributed to aging in line with Confucianism. They found that Japanese older adults scored higher on personal growth compared to younger counterparts, whereas the opposite age pattern was found in the US. Interestingly, purpose in life 
showed decrease in both samples which the authors interpreted as difficulties to provide meaningful involvement opportunities for elders in technologically highly advanced societies. Hedonic aspects of well-being were reported to increase (positive emotions) respectively decrease (negative emotions) in both samples, whereas Fang et al. (2017) have referred to a decrease of negative affect in particular for US elder adults. This latter finding was again explained according to independent and interdependent orientations: whereas for Westerners positive emotions might be important enhancing their self-esteem in line with cultural values of independence and autonomy, for the more interdependently oriented Easterners it could be important to attend to both positive and negative information in order to establish harmonious social relations.

\section{Preparing for old age}

Preparing for anticipated changes in older age might help to tackle challenges related to aging and thus be beneficial for well-being later on. Kornadt and colleagues (2018) found differences in preparation for older age between adults in the US, Germany and China (Hong Kong). Participants from the US and Germany reported generally more preparation compared to participants from Hong Kong, but cross-cultural variation was also found depending on domains of preparation (such as health care, work, finances, social relations, end-of-life concerns). Apart from diverging welfare policies, these East-West differences were also in line with culture-specific expectations of passive vs. active age in Eastern compared to Western elders.

\section{Informal care}

In light of population aging, the issue of care is highly prominent as old age is still associated with a high probability of physical and functional impairments (Ferring 2010). Although family remains an important pillar in old age support provision all over the world, 
cultural norms and expectations about responsibilities for care differ largely, and even among European countries policies and practices vary, with higher public care provisions in the North and more intense family care in the South (Dykstra 2017). Different care preferences and expectations for mutual support are related to cultural values and norms (for a summary see Albert et al. in press). According to the Confucian value of filial piety the eldest son and his wife are responsible for care of elder parents (Hwang 1999) and a high familism goes along with a preference for informal care also in Southern and middle America (Crist et al. 2009; Hwang 1999). However, due to social change traditional patterns can be adapted, as has been shown for urban contexts in China where daughters might take over care responsibilities as the traditionally rather preferred sons and their wives might not be available (for a summary see Pinquart et al. 2018).

\section{Future Directions for Research}

In this final section directions for further research will be discussed, emphasizing both new theoretical perspectives and methodological tools for enhancing cross-cultural psychogerontological research.

\section{Theoretical perspectives}

A simple transfer of Western based theories and concepts such as future time perspective might not hold in other contexts as cultural beliefs (such as spirituality or religion) might bias goals and behavior. For instance, cultures differ in how they structure the life course, how they see afterlife and their relations with ancestors (Arnett 2016). In addition, aspects of acculturation and multiculturalism should also be taken into account. For instance, one could ask how social networks and psychological aspects of aging are affected by migration from a more collectivist to 
a more individualistic context (see also Burholt et al. 2017), or how biculturals deal with challenges of aging.

\section{Methodological challenges}

Studies on cross-cultural differences and culture-specifics in aging are often based on cross-sectional design of most studies. Differences between cultures could indicate cohort rather than age effects in light of societal change. As a consequence, more longitudinal and cohortsequential studies might be conducted in cross-cultural psychogerontological research. Also, whereas most studies have focused on East-West comparisons—often US and European vs. East Asian samples, inclusion of further countries seems highly needed to gain a deeper insight into culture-specifics. At the same time, clustering countries as Eastern or Western seems too simplifying, as within these broad categories cultural contexts vary largely, thus a thorough description of cultural contexts is needed beyond dichotomies such as individualist-collectivist. Finally, culture-specific aging experiences might not be fully grasped by quantitative survey data and caution is needed when using Western based questionnaires without cultural adaptation.

\section{Summary}

The present entry focused on cultural similarities and differences with regard to aging. After describing typical developmental pathways of independence and interdependence that guide human development, selected research findings regarding views on aging, cognitive development, social relations, well-being, preparation for old age and care arrangements were described. Finally, new approaches and suggestions for future research were outlined such as a closer look at the culture-specific meaning of Western concepts that cannot be transferred into other cultural contexts without any changes. 


\section{Cross-References}

Intergenerational family caregiving in welfare policy context, Filial piety and responsibilities among the Chinese, Successful aging 2.0, Geropsychology/psychogerontology, Life-span development, Self-perceptions of aging

\section{References}

Ajrouch KJ, Fuller HR, Akiyama H, Antonucci TC (2018) Convoys of social relations in crossnational context. Gerontologist 58(3):488-499. doi: 10.1093/geront/gnw204

Albert I, Schwarz B, Mayer B, Trommsdorff G (in preparation) Familiale Generationenbeziehungen (international). In: Ecarius J, Schierbaum A (eds), Handbuch Familie. Springer VS

Albert I, Trommsdorff G (2014) The Role of Culture in Social Development Over the Life Span: An Interpersonal Relations Approach. Online Readings in Psychology and Culture 6(2). doi: $10.9707 / 2307-0919.1057$

Arnett JJ (2016) Life stage concepts across history and cultures: Proposal for a new field on indigenous life stages. Hum Dev 59:290-316. doi:10.1159/000453627

Baltes PB (1993) The aging mind: potential and limits. Gerontologist 33(5): 580-94

Baltes PB, Reese HW, Lipsitt LP (1980) Life-span developmental psychology. Annu Rev Psychol 31:65-110. doi:10.1146/annurev.ps.31.020180.000433

Bleidorn W, Arslan RC, Denissen JJ, Rentfrow PJ, Gebauer JE., Potter J, Gosling SD (2016) Age and gender differences in self-esteem-A cross-cultural window. J Pers Soc Psychol 111(3):396-410 
Brinkmann S, Musaeus P (2018) Coming of age in a youthful culture: A commentary from cultural psychology. In: Boll T., Ferring D, Valsiner J (eds) Cultures of care in aging. Information Age Publishing, Charlotte, NC, p. 83-96

Burholt V, Dobbs V, Victor C (2017) Social support networks of older migrants in England and Wales: the role of collectivist culture. Ageing Soc:1-25

Carstensen LL, Fung H, Charles ST (2003) Socioemotional selectivity theory and the regulation of emotion in the second half of life. Motiv Emotion 27(2):103-123

Chasteen AL, Cary LA, Iankilevitch M (2015) Age Stereotyping and Discrimination. In: Pachana N. (ed) Encyclopedia of Geropsychology. Springer, Singapore

Crist JD, Mcewen MM, Herrera AP, Kim SS, Pasvogel AE, Hepworth J (2009) Caregiving burden, acculturation, familism, and Mexican American elders' use of home care services. Res Theory Nurs Pract 23(3):165-180

Dykstra P (2017) Cross-national differences in intergenerational family relations: The influence of public policy arrangements. Innov Aging. doi:10.1093/geroni/igx032

Erikson EH (1968) Identity. Youth and crisis. Norton, New York

Fang Y, Gong X, Lu M, Fung HH (2017) Cross-cultural aging. In: Pachana NA (ed) Encyclopedia of Geropsychology. Springer, Singapore

Ferring D (2010) Intergenerational relations in aging societies: Emerging topics in Europe. J Intergener Relatsh 8(1):101-104. doi:10.1080/15350770903520833

Greenfield PM, Keller H, Fuligni A, Maynard A (2003) Cultural pathways through universal development. Annu Rev Psychol 54:461-490. doi:10.1146/annurev.psych.54.101601.145221 
Hwang, K.-K. (1999). Filial piety and loyalty: Two types of social identification in Confucianism. Asian J Soc Psychol 2:163-183

Kağıtçıbaşı, Ç. (1982). Old-age security value of children: Cross-national socioeconomic evidence. J Cross Cult Psychol 13:29-42

Kanagawa C, Cross SE, Markus HR (2001). 'Who am I?' The cultural psychology of the conceptual self. Pers Soc Psychol B 27(1): 90-103

Karasawa M, Curhan KB, Markus HR, Kitayama SS, Love GD, Radler BT, Ryff CD (2011) Cultural perspectives on aging and well-being: A comparison of Japan and the U.S. Int J Aging Hum Dev 73(1):73-98. doi:10.2190/AG.73.1.d

Kemper LE, Bader AK, Froese FJ (2016) Diversity management in ageing societies: A comparative study of Germany and Japan. Manag Rev 27(1-2):29-49

Kornadt AE, Rothermund K (2015) Views on aging: Domain-specific approaches and implications for developmental regulation. Annu Rev Gerontol Geriatr 35(1):121-144. doi:10.1891/0198-8794.35.121

Kornadt A, Voss P, Fung HH, Hess TM, Rothermund K (2018). Preparation for Old Age - The Role of Cultural Context and Future Perceptions. J Gerontol B Psychol Sci Soc Scidoi:10.1093/geronb/gby075

Löckenhoff CE, De Fruyt F, Terracciano A, McCrae RR., De Bolle, M., Costa, P. T., ... Yik, M. (2009). Perceptions of aging across 26 cultures and their culture-level associates. Psychol Aging 24(4):941-54 
Mayer B, Trommsdorff G, Kagitcibasi C, Mishra RC (2012) Family models of independence/interdependence and their intergenerational similarity in Germany, Turkey, and India. Fam Sci 3(1):64-74

Neugarten BL, Moore JW, Lowe JC (1965) Age norms, age constraints, and adult socialization. Am J Sociol 70:710-717

North MS, Fiske ST (2015) Modern attitudes toward older adults in the aging world: A crosscultural meta-analysis. Psychol Bull 141(5):993-1021. doi:10.1037/a0039469

Park D, Gutchess A (2006) The cognitive neuroscience of aging and culture. Curr Dir Psychol Sci 15(3):105-108. doi:10.1111/j.0963-7214.2006.00416.x

Park DC, Nisbett R, Hedden T (1999) Aging, culture, and cognition. J Gerontol B54B(2): P75P84. doi:10.1093/geronb/54B.2.P75

Pinquart M, Soerensen S, Song Y (2018) Older persons care-related preferences: Cultural and cross-cultural influences. In: Boll T, Ferring D, Valsiner J (eds) Cultures of care in aging. Information Age Publishing, Charlotte, NC, p 123-148

Rothbaum F, Pott M, Azuma H, Miyake K, Weisz J (2000) The development of close relationships in Japan and the United States: Paths of symbiotic harmony and generative tension. Child Dev 71:1121-1142. doi:10.1111/1467-8624.00214

Triandis HC (2001) Individualism-collectivism and personality. J Pers 69:907-924

Valsiner J (1996) Co-constructionism and development: A socio-historic tradition. Anuario de Psicologia 69:63-82 
Westerhof GJ, Dittmann-Kohli F, Katzko MW (2000) Individualism and collectivism in the personal meaning system of elderly adults: The United States and Congo/Zaire as an example. J Cross Cult Psychol 31(6):649-676. doi:10.1177/0022022100031006001

Wrosch C, Heckhausen J (2005) Being on-time or off-time: Developmental deadlines for regulating one's own development. In: Perret-Clermont AN, Barrelet JM, Flammer A, Miéville D, Perret JF, Perrig W (eds) Thinking time: A multidisciplinary perspective. Hogrefe \& Huber Publishers, Göttingen, p 110-123

United Nations, Department of Economic and Social Affairs, Population Division (2017) World Population Prospects: The 2017 Revision, Key Findings and Advance Tables. Working Paper No. ESA/P/WP/248. https://population.un.org/wpp/Publications/ Accessed 10 May 2019 